\title{
Senior High School Students' Reading Comprehension of Graded Readers
}

\author{
Lu-Fang Lin \\ Institute of Applied English, National Taiwan Ocean University \\ 2 Pei-Ning Road, Keelung 202, Taiwan, R.O.C. \\ Email: annalin@mail.ntou.edu.tw
}

\begin{abstract}
This study investigates senior high school students' reading comprehension of graded readers outside of the classroom. Seventy-eight participants were assigned to read three graded readers written respectively from 600-word, 1200-word, and 1700-word wordlists and labeled as Level 2 (L2), Level 3 (L3), and Level 4 (L4). All participants completed post-reading comprehension tests, follow-up reading tests, and post-reading questionnaires. $T$-test results showed that first, females' reading comprehension ability had grown significantly. Second, there were no significant differences between males and females' comprehension of $L 2$ and $L 3$ readers, but females achieved significantly higher scores than males in $L 4$ graded reader. Third, females significantly used more strategies than their counterparts to understand L4 graded reader. Finally, the interpretation of females' adding and reducing the strategies to comprehend difficult text were provided. Instructional suggestions for senior high school students' outside reading were presented.
\end{abstract}

Index Terms-extended reading activity, graded readers, reading comprehension, reading strategies

\section{INTRODUCTION}

Reading efficiency relies on rapid and automatic tasks of word recognition, retrieve and application of proper world knowledge (Lin, 2008, 2009b). This integrated process can be trained by extensively expose to second language (L2) texts through reading. As Grabe (2002) pointed out that most reading curricula in school did not provide L2 learners sufficient time to develop their reading skills. The instructors encourage their students to practice reading skill further out of the class. Extensive reading (ER) is currently the most easily utilized approach to reading efficiency. Over the past decade, there have been many studies focusing on ER and even in the turning period of the $21^{\text {st }}$ century the ER research still cause attention in both foreign and second language contexts (Bell, 2001; Camiciottoli, 2001; Jacobs \& Gallo, 2002; Powell, 2002). As well, the ER program's benefits for first- and second-language learners are well reported that ER is positively related to literacy development (Coady, 1997; Day \& Bamford, 1998; Krashen, 2001). More specifically, ER effectively lead L2 learners to read fluently (Hill, 1997), to recognize sight vocabulary automatically (Day \& Bamford, 1998), to reinforce L2 learners' vocabulary (Nation, 1997), to wean off excessive dictionary use (Brown, 2000) and to develop positive attitude (Day \& Bamford, 2002). From the ER literature, it can be found that relatively few studies focused on male and female learners' reading performance in an extended reading activity. In this study, reading materials at three levels of difficulty were used to examine whether there were significant differences between male and females student reading comprehension in an outside reading program.

\section{A. Gender and Language Learning Strategies}

Previous strategy studies examining gender differences focused on language learning strategies (LLS). Most of the LLS studies were conducted using Oxford's (1990) Strategy Inventory for Language Learning (SILL) which is a 50-item survey designed to reveal the self-reported language learning strategies that second and foreign language learners use. SILL-based studies have been conducted with males and females of different language backgrounds. Using 374 college students in Puerto Rico as participants, Green and Oxford (1995) found that men and women differed on nearly one-third of the strategies on the SILL (15 0f 50), inclusive of memory, cognitive, metacognitive, affective, and social strategies; females used more strategies than men in all six categories. South African students' application of strategies was examined by Dreyer and Oxford (1996). The results of their study showed that women applied social and metacognitive strategies more often than men. Oxford and Ehrman's (1995) study also revealed that women used strategies more frequently than men. Using Taiwanese children as participants, Lan and Oxford (2003) found that out of 50 strategies there were eleven significant differences in strategy usage between girls and boys, with these differences in favor of greater strategy use by girls. However, some other SILL research revealed inconsistent results of gender effects on strategy usage. For example, Szoke and Sheorey (2002) found that for Hungarian and Russian learners, there were no differences between men and women in individual strategies and the six categories. Using video segments as learning materials, gender differences were found (Lin, 2009a).

\section{B. Gender and Reading Performance}


Oxford (2002) stated that "females are superior in verbal skills, while males are superior in spatial skills" (p. 252). Overall earlier research demonstrated that gender played a role in reading achievement. For example, girls reported higher interests in reading activity than boys (Guthrie \& Greaney, 1991) and girls tended to be more motivated to read (Wigfield \& Guthrie, 1997). As well, girls preferred to read more books than boys (Elley, 1994). Overall, girls had better reading comprehension, read more frequently, and had a more positive attitude to reading (Logan \& Johnston, 2009). As to reading comprehension tests, significant differences favoring females were also found in earlier studies (Lynch, 2002; Elley, 1994). Chiu and McBride-Chang (2006) conducted a large-scale cross-cultural study and concluded that there were significant gender differences in reading comprehension; girls' mean reading scores exceeded that of boys across 43 countries. However, some earlier studies revealed that there were no differences in reading comprehension (Hogrebe, Nist, \& Newman, 1985; Rosen, 2001). In addition to the investigation of whether there were significant differences in reading comprehension between males and females, the present study extended earlier studies by further examining time spent on reading and reading strategy use in an extended reading context.

\section{Gender and Reading Strategies}

The literature on gender and reading strategies does not show sufficient knowledge of strategy utilization for either males or females, although there have been relatively few studies on reading strategies. One of the few studies that specifically examine male/female differences in reading strategies is that of Sheorey and Mokhtari (2001). In their study, 152 ESL students at a US university completed a reading strategy questionnaire. The results showed there were no significant differences between men and women in overall cognitive, metacognitive and support strategies, with only one individual strategy differing significantly. Phakiti (2003) also investigates how 384 male and female Thai college students used cognitive and metacognitive strategies. By analyzing the questionnaire responses, Phakiti (2003) reported that there were significant differences between men and women in the use of cognitive strategies; males used significantly more metacognitive strategies than their female counterparts. While the data concluded from Sheorey and Mokhtari (2001) and Phakiti (2003) shed light on gender differences and reading strategy use, more research needs to be done to draw generalized conclusion about how male and female second language learners use reading strategies to comprehend the text. Examining reading strategies applied by 248 advanced college ESL students, Poole (2005) found that men and women did not significantly differ in their overall strategy use. As Poole (2005) suggested that more research need to be done to draw generalized conclusion about how male and female L2 learners use reading strategies to comprehend the text.

Three decades ago, researchers of the good-poor reader studies were aware that those who achieved a high level of second language proficiency were active strategy users (Hosenfeld, 1977). Furthermore, Anderson (1991) conducted research with native Spanish-speaking university level intensive ESL students and the results further confirmed that the more strategies a reader used, the higher scores he/she might receive on the comprehension measures. The success of reading may also depend on the condition when the reader applies strategies appropriately. Some studies further investigated reading strategies used by good and poor readers and identified some characteristics of good and poor readers' application of reading strategies (Block, 1986; Massaro \& Miller, 1983; Sarig, 1987; Vellutino, Scanlon, \& Tanzman, 1998). For example, there is one possible difference on good and poor readers' memory task; that is, poor readers are less automatic in word recognition and thus use more available memory space simply to complete the mechanical way of reading (Massaro \& Miller, 1983) and moreover, poor readers are limited with their abilities and not mature enough to use strategies flexibly and automatically. In contrast, good readers are more able to monitor their comprehension, more conscious of their strategy use, and even flexible enough to use the strategies than their counterparts. Given that research on differentiating good readers' from poor readers' strategy use, research on readers' strategies may agree that readers who are able to use reading strategies or have learned reading strategies may have few problems with comprehension (Anderson, 1999; Garner, 1990; Nist \& Holschuh, 2000; Sheorey \& Mokhtari, 2001; Simpson \& Nist, 1997). From the abovementioned literature, it can be noted that the success of second language reading relies mostly on the application of strategies.

\section{Research Purposes and Questions}

Reading strategies investigated in this current study centered on the reader's general and linguistic levels of knowledge. The strategies discussed in the current study only focused on cognitive elements, especially on how readers utilize their knowledge to comprehend text. The knowledge included the reader's world knowledge and linguistic knowledge of sentences and words.

The purpose of the study first was to investigate male and female L2 learners' comprehension of graded readers out of the class. Second, the present study examined whether the amount of time and the number of strategies males and females used to comprehend graded readers could be significant factors influencing students' reading comprehension. Specifically, the study distinguished the strategies of the participants' using their world, sentence and word knowledge to comprehend different difficulty levels of text. Third, the study was to explore why and how the participants selected strategies to comprehend reading materials at different difficulty levels. The following questions were used to guide this study:

1 Are there any significant differences between male and female participants' reading comprehension of graded readers at different difficulty levels? 
2. Are there any significant differences between male and female participants' time spent on reading graded readers at different difficulty levels?

3. Are there any significant differences between male and female participants' reading strategy use when they read graded readers at different difficulty levels?

4. What are male and female participants' perception of reading strategy use?

\section{Methodology}

\section{A. Participants}

A total of seventy-eight senior high school students of English as a foreign language (EFL) joined this study. The tenth-grade participants studied in the same school in Taiwan. Their mother language was Mandarin. All of them never stayed in English speaking countries for over half a year.

\section{B. Instruments}

Four instruments were used and individually described in the order of manipulation in the study from the first to the last.

\section{Background questionnaire}

In the first meeting, a background questionnaire was conducted to collect information of the participants' backgrounds, including their native language, the length of staying in English speaking countries, and experience with outside reading.

\section{Reading comprehension pre- and post-tests}

The pre- and post-tests were group tests featuring the same text, which measured the participant's ability to comprehend writing in English. This test consisting of two sections measured the participants' knowledge of vocabulary and grammar. Each section included 25 multiple-choice questions (four choices for each question). The maximum score for each section was 25 , with one correct response one point.

The rationale for using the same test for both pre- and post-measurement was to assure objectively comparable tests, thus avoiding the problem of equating different formats of pre- and post-tests. The ten-week interval between administrations was considered long enough to control for any short-term memory effects. This is because the participants were not provided with the correct answers after the pre-test, so they had no way of knowing whether their answer was correct; moreover, they were unlikely to remember how they had answered a question the first time. Thus, the interval was deemed long enough to control for any significant learning except for that due to the training.

\section{Follow-up reading tests}

There are three follow-up reading tests. Each test has the same format: The participants answered 20 multiple-choice questions related to the content of the assigned graded reader. One correct response valued one point and the total score is 20 for each test. The alphas for three tests were $.85, .82$ and .88 .

\section{Post-reading questionnaires}

After reading a graded reader, each participant also filled up a questionnaire in class. In total, each participant filled up three questionnaires, which contained the same questions and had the same format. The questionnaire consisted of four questions (see Appendix). The first question asked the participants to select the strategies they used among three strategies such as, the word meanings (WM) strategy, the sentence structure (SS) strategy, and the world knowledge (WK) strategy. Prior to the participant's filling out the questionnaire, the researcher informed the participants that they could choose one or more strategies to answer this question. The researcher provided the participants Chinese explanation of the three strategies. The WM strategy referred to using Chinese definition of words. The SS strategy referred to using grammatical rules to analyze the sentences, such as the subject, the verb, and the object, or the tenses like the present, the past and the future. The WK strategy referred to using the participants' general world knowledge related to the content of the story. In developing the questionnaire, the researcher placed the emphasis on the comprehension strategy, which reveals a reader's resources for comprehending the text. The three strategy options were designed based on Block's (1986) taxonomy, which categorized strategies into two levels: general comprehension and local linguistic strategies. By following Block's (1986) strategy divisions, the WM strategy and the SS strategy belong to local linguistic levels and the WK strategy, general comprehension level.

\section{Graded Readers}

For some reading programs, extensive reading by definition is the reading of graded readers (Bamford, 1984). In this study, an extensive reading was conducted and the researcher used graded readers as reading material. The participants were asked to read three books selected from Penguin reader series. The three books were at Level 2 (L2), Level 3 (L3), and Level 4 (L4) respectively. This series is designed for EFL/ESL students with simplified sentence structures and controlled vocabulary frequency. The book at L2 entitled A Christmas Carol was written from a 600-word wordlist, L3, entitled Forest Gump, from 1200 words, and L4, entitled The Client, from 1700 words. These books were published by Pearson Education Limited. The participants started to read them from L2 to L4. To avoid a tight schedule, the duration for the participants to read each book was two weeks. 


\section{RESULTS AND DISCUSSION}

\section{A. Reading Comprehension of Male and Female Participants}

To respond the question of whether there are significant differences between male and female participants' reading comprehension, $t$-tests were conducted to compare the scores of reading comprehension pre- and post-tests and those of follow-up reading tests. The sample was made up of two groups (i.e., female and male groups).

Table 1 presents both genders' perception of the difficulty level of three graded readers. As shown in Table 1, the participants clustered around Medium Option of three graded readers; however, three participants ranked L2 reader as a difficult reader. From L2 to L4, there were a decreasing tendency for both genders' percentage of Easy Option and an increasing tendency of Difficult Option.

TABLE 1

THE FREQUENCY OF TEXT DIFFICULTY PERCEIVED BY MALE AND FEMALE PARTICIPANTS FOR THREE GRADED READERS

\begin{tabular}{|c|c|c|c|c|c|c|c|}
\hline \multirow{2}{*}{ Gender } & \multirow{2}{*}{$\begin{array}{c}\text { Text } \\
\text { Difficulty }\end{array}$} & \multicolumn{2}{|c|}{ L2 } & \multicolumn{2}{|c|}{ L3 } & \multicolumn{2}{|c|}{$\mathrm{L} 4$} \\
\hline & & Number & $\%$ & Number & $\%$ & Number & $\%$ \\
\hline Male & Difficult & 2 & 5.26 & 4 & 10.53 & 6 & 15.79 \\
\hline$(n=38)$ & Medium & 28 & 73.68 & 26 & 68.42 & 28 & 73.68 \\
\hline & Easy & 8 & 21.05 & 8 & 21.05 & 4 & 10.53 \\
\hline Female & Difficult & 1 & 2.50 & 2 & 5.00 & 6 & 15.00 \\
\hline$(n=40)$ & Medium & 29 & 72.50 & 30 & 75.00 & 31 & 77.50 \\
\hline & Easy & 10 & 25.00 & 8 & 20.00 & 3 & 7.50 \\
\hline
\end{tabular}

Table 2 presents mean scores (M) and standard deviations (SDs) for male and female groups' reading comprehension pre- and post-tests. In the pre-test, male group and female group, respectively, answered $69.37 \%$ and $69.5 \%$ correctly. In the post-test, male and female groups, respectively, answered $71.05 \%$ and $76 \%$ correctly. In general, both groups increased in the post-tests; female group improved by $6.5 \%$, from $69.5 \%$ in the pre-test to $76 \%$ in the post-test; on the other hand, male group improved by $1.68 \%$, from $71.05 \%$ to $69.37 \%$. The results of Table 2 further indicated that there was no significant difference between male and female groups' mean scores on the pre-test $(t=-.06, p=.95>0.05)$. Female group's reading comprehension ability is similar to that of male group before the outside reading program started. However, there was a significant difference between the mean scores of the two groups on the post-test $(t=$ $-2.35, p=.02<0.05)$. Female group achieved significantly higher scores than male group in the post-test. Moreover, comparisons between each gender group's pre-and post-tests show that females' post-test score was higher than their pre-test score by $6.5 \%$ and male group was $2.68 \%$. In general, this result revealed that females' reading comprehension ability had grown considerably, suggesting that this outside reading program fostered females' reading comprehension better than their male counterparts. This finding is coherent with earlier reading research on gender difference that females performed better reading comprehension (Logan \& Johnston, 2009; Chiu \& McBride-Chang, 2006; Lynch, 2002; Guthrie \& Greaney, 1991; Elley, 1994).

TABLE 2 .

MALE AND FEMALE GROUPS' CORRECT PERCENTAGE SCORES OF PRE- AND POST-READING COMPREHENSION TESTS

\begin{tabular}{|c|c|c|c|c|c|c|}
\hline \multirow[b]{2}{*}{ Test } & \multicolumn{2}{|c|}{ Male $(n=38)$} & \multicolumn{2}{|c|}{ Female $(n=40)$} & \multirow[b]{2}{*}{$t$} & \multirow[b]{2}{*}{$p$} \\
\hline & $\mathrm{M}$ & S.D. & M & S.D. & & \\
\hline Vocabulary Pre-test & 69.05 & 9.19 & 68.70 & 8.73 & -0.17 & 0.86 \\
\hline Grammar Pre-test & 69.68 & 9.56 & 70.30 & 11.24 & -0.26 & 0.80 \\
\hline Total Pre-test & 69.37 & 8.55 & 69.50 & 9.19 & -0.06 & 0.95 \\
\hline Vocabulary Post-test & 70.32 & 10.79 & 75.50 & 7.54 & -2.47 & $0.01 *$ \\
\hline Grammar Post-test & 71.79 & 11.31 & 76.50 & 11.14 & -1.85 & 0.07 \\
\hline Total Post-test & 71.05 & 10.01 & 76.00 & 8.44 & -2.35 & $0.02^{*}$ \\
\hline
\end{tabular}

Table 3 shows the descriptive statistics (i.e. the means, standard deviations [SDs], standard error means) for the scores on follow-up reading tests of L2, L3 and L4 graded readers by male and female participants. Across three graded readers, males consistently decreased their scores in follow-up tests from L2 to L4. The data in Table 1 also supported this result, indicating that males reported decreasing percentage scores in Easy Option, but increasing percentage scores in Difficulty Option from L2 to L4.

As shown in Table 3, female participants achieved almost the same mean score as male participants at L2 test, but reversely, female participants achieved the highest average mean score in L4, which was also higher than that of male participants. The $t$-test results showed that there were no significant differences between test scores for males and females in L2 test and L3 test. However, there was a significant difference between male and female participants' mean scores of L4 test $(t=-4.09, \mathrm{p}<.05)$. This means that when reading graded readers at L2 and L3, male participants scored almost the same correct response as female participants; however, when reading L4 graded reader, female participants outperformed male participants. The results suggested that with the raise of text difficulty, females comprehend text better than males. Compared to males, females had fewer problems in comprehending the content and hence performed better in reading. This result is also in line with the conclusion from previous good-poor reader 
comparison research that good readers who used strategies flexibly have fewer comprehension problems than poor readers (Anderson, 1991; Garner, 1990; Nist \& Holschuh, 2000; Simpson \& Nist, 1997).

TABLE 3.

DIFFERENCES BETWEEN MALE AND FEMALE PARTICIPANTS' PERCENTAGE SCORES OF FOLLOW-UP TESTS FOR THREE GRADED READERS

\begin{tabular}{|c|c|c|c|c|c|c|}
\hline \multirow[b]{2}{*}{ Graded reader } & \multicolumn{2}{|c|}{ Male $(n=38)$} & \multicolumn{2}{|c|}{ Female $(n=40)$} & \multirow[b]{2}{*}{$t$} & \multirow[b]{2}{*}{$p$} \\
\hline & $\mathrm{M}$ & S.D. & $\mathrm{M}$ & S.D. & & \\
\hline L2 & 78.55 & 15.06 & 78.38 & 13.46 & 0.06 & 0.96 \\
\hline L3 & 69.87 & 14.73 & 75.00 & 13.45 & -1.61 & 0.11 \\
\hline L4 & 68.55 & 15.11 & 81.13 & 11.90 & -4.09 & $0.00^{*}$ \\
\hline
\end{tabular}

\section{B. Reading Strategy Use of Male and Female Participants}

As shown in Table 4, from L2 to L4 graded readers, both gender groups increased the use of strategies. The average number of strategies applied by males increased slightly; on the other hand, the positive trend for females' strategy use boomed at L4 graded reader. The $t$-test results demonstrated that the differences between the numbers of strategies utilized by males and females were not significant at L2 and L3 graded readers, but the difference was significant at L4 graded reader $(t=-2.53, p<.05)$. That is, females obviously used more strategies than males to comprehend L4 graded reader. This result also supported the previous result concluded in post-reading comprehension tests that females comprehended L4 reader more successfully than males. This result was consistent with earlier research indicating that successful language learners used more strategies than unsuccessful learners (Anderson, 1991). The results suggest that gender can be an essential factor influencing strategy application.

TABLE 4.

DIFFERENCES BETWEEN THE NUMBERS OF STRATEGIES USED BY MALES AND FEMALES

\begin{tabular}{|c|c|c|c|c|c|c|}
\hline \multirow[b]{2}{*}{ Graded reader } & \multicolumn{2}{|c|}{ Male $(n=38)$} & \multicolumn{2}{|c|}{ Female $(n=40)$} & \multirow[b]{2}{*}{$t$} & \multirow[b]{2}{*}{$p$} \\
\hline & $\mathrm{M}$ & S.D. & $\bar{M}$ & S.D. & & \\
\hline L2 & 1.76 & 0.75 & 1.80 & 0.61 & -0.24 & 0.81 \\
\hline L3 & 1.79 & 0.70 & 1.95 & 0.71 & -0.99 & 0.32 \\
\hline $\mathrm{L} 4$ & 1.84 & 0.75 & 2.25 & 0.67 & -2.53 & $0.01^{*}$ \\
\hline
\end{tabular}

As shown in Table 5, both gender groups reported similar tendency of strategy use. WM strategy was employed the most frequently, WK strategy, the second, and SS strategy, the least. Both genders mainly relied on local linguistic level of strategy. They tended to figure out the word meanings. Moreover, there was a significant difference in WM strategy use between males and females' strategy use; that is, females applied WM strategy significantly more frequently than males. This attributes to females' high interest and motivation in reading and they would like to read the story in details.

TABLE 5.

STRATEGIES USED BY MALE AND FEMALE PARTICIPANTS ACROSS L2, L3, AND L4 GRADED READERS

\begin{tabular}{|c|c|c|c|c|c|c|}
\hline \multirow[b]{2}{*}{ Strategies } & \multicolumn{2}{|c|}{ Male $(n=38)$} & \multicolumn{2}{|c|}{ Female $(n=40)$} & \multirow[b]{2}{*}{$t$} & \multirow[b]{2}{*}{$p$} \\
\hline & $\mathrm{M}$ & S.D. & $\mathrm{M}$ & S.D. & & \\
\hline WM & 2.32 & 0.81 & 2.83 & 0.38 & -3.58 & $0.00^{*}$ \\
\hline SS & 1.08 & 0.97 & 1.08 & 0.99 & 0.02 & 0.98 \\
\hline WK & 2.00 & 0.96 & 2.10 & 1.10 & -0.43 & 0.67 \\
\hline
\end{tabular}

\section{C. $\quad$ Time Spent on Reading Graded Readers}

Table 4 summarized the descriptive statistics. Both gender spent the least amount of time reading L2 reader, and the most time, L4 reader. The result revealed that both males and females, on average, spent more and more time reading these graded readers as text difficulty increased. It can be noted that when reading graded readers from L2 to L4, the average time for males varied from 2.6 hours to 5.2 hours whereas females ranged from 3.1 hours to 4.5 hours. In the beginning females spent more time than males, but at the end the situation was reverse. Males increased by 2.6 hours and females by 1.4 hours. As a whole, female participants' time span was much shorter than that of males. By considering males' L4 reading comprehension test result, it can be noted that more time did not produce greater comprehension. Females' successful comprehension of L4 attributes to the reason that female participants learn how to flexibly use strategies which employ their word, sentence, and world knowledge and consequently perform reading efficacy. The following section provided qualitative interpretation to further explain this. 
TABLE 6

DIFFERENCES BETWEEN MALES AND FEMALES' TIME SPENT READING THREE GRADED READERS

\begin{tabular}{|c|c|c|c|c|c|c|}
\hline \multirow[b]{2}{*}{ Graded reader } & \multicolumn{2}{|c|}{ Male $(n=38)$} & \multicolumn{2}{|c|}{ Female $(n=40)$} & \multirow[b]{2}{*}{$t$} & \multirow[b]{2}{*}{$p$} \\
\hline & $\mathrm{M}$ & S.D. & $\mathrm{M}$ & S.D. & & \\
\hline $\mathrm{L} 2$ & 2.62 & 1.35 & 3.11 & 1.77 & -1.38 & 0.17 \\
\hline L3 & 3.65 & 2.25 & 3.22 & 1.32 & 1.01 & 0.32 \\
\hline $\mathrm{L} 4$ & 5.19 & 3.88 & 4.50 & 1.86 & 1.02 & 0.31 \\
\hline
\end{tabular}

\section{Qualitative Interpretation of the Participants' Strategy Use}

In this section, two themes were categorized: first, illustrations of successful and unsuccessful comprehension in terms of reports collected from female participants with high test scores, and male participants with low test scores. The results received from quantitative analysis revealed that females performed successful reading comprehension. The second section was to present the interpretation of female participants' adding and reducing strategies during the process of reading the graded reader varied in text difficulty. Extracts from female participants' questionnaire response were used as supplementary data.

\section{Illustrations of successful and unsuccessful comprehension}

From the questionnaire response, 12 out of 40 female participants achieving high scores expressed that when they read the three storybooks, they never noticed the single words but a series of words. During the process of reading, they just read through the lines and used Chinese to construct a general idea of the story. Another three participants explained that they did not paid attention to sentence structures because most structures were simple and consistent. Five participants stated that they had a discussion at school about the details of the story and the characters and also tried to find the film to view. The story discussion displayed females' interests in reading and this further supported Elley's (1994) and Logan and Johnston's (2009) opinion that girls' interest and positive attitudes to reading resulted in their high score in reading comprehension score.

As to male participants, the cases who achieved low scores in post-reading comprehension test were extracted to explain why they could not performed significantly better comprehension than females. Eleven male participants described they had no idea about the grammar so they would not like to use the SS strategy. They said they spent much time in reading each word in the text. After reading a sentence, they tried to use Chinese to connect each word together. They were stuck by words frequently. Without Chinese meanings, they could not continue to read the story any further. Specifically, one male participant expressed that when reading each story, he almost lost his patience and could not even read the first few pages of the story any more, so he stopped reading at home. When he came to school, he asked his friend to tell him the plot of the story in Chinese chapter by chapter; afterwards, he followed the Chinese interpretation to read the story. As a result, the Chinese definition is an essential element to these participants' understanding of English text.

In addition, nine males spending more than five hours reading the story stated that the vocabulary was an essential factor to their comprehension of English text. When they confronted the sentences they could not understand, they intuitionally reread the sentence word-by-word again and again, then assigned the familiar word with Chinese definitions, and tried to translate the whole sentence. However, they said that under most situations they still could not make sense of the sentence because the unfamiliar word was the key to the meaning of the sentence. Then they sometimes used the SS strategy to segment the sentence into a verb, a noun or an adjective. However, they expressed that it was in vain to do that because their limited SS knowledge prevented them from parsing the sentences into correct grammatical chunks.

\section{Female participants' adding the number of strategies}

The aforementioned results indicated that the more difficult the text is, the more strategies female participants use and the better comprehension they perform. In this section, the response to the second and third question in the questionnaire was categorized to figure out the reasons why the participants increased the number of strategies to comprehend more difficult reading materials. Generally, Wk is the major strategy used by females. This result is consistent the research by Lin (2009b) that prior knowledge plays important role in reading comprehension. Five illustrations of adding strategies were presented.

First, WK adding WM and SS. One participant stated that when she read the story at L2 she used her WK only. When she read L3 graded reader, composed of more new vocabulary and more complicated sentence structures than the first one, she added WM and SS strategies.

Second, WM adding SS. Another female participant expressed that she just used the WM strategy when reading the first story. When she read the third one, she felt that sentences were longer and more complex than the first one so she added the SS strategy. This is because the teacher taught them to analyze the structures of the sentences to comprehend the article in class. Hence, she assumed SS strategy be a good way to understand more complex English text.

Third, WK adding WM. Another female described that she played a role in the L2 story when she was in the kindergarten so she used WK strategy while reading this story. When she read L3 graded reader, she added WM strategy because she found that there were conflicts between her WK and the story. She explained further that what the main character did in the story was extraordinary and out of her imagination; in her opinion, it was impossible for a 
slow-witted person to experience such luckiness in the reality. Thus, she read the story word-by-word repeatedly to ensure the exact meaning of the sentences.

Fourth, WM and SS adding WK. Another participant expressed that this was her first time to read such kind of storybook and she felt interested in how the story was described in English. When she read L2 graded reader, she focused on words and sentences in great proportion. Then when she read L3 graded reader, she added WK strategy because she had previously viewed the film and had a general concept about the story. Furthermore, She expressed that she used all three strategies to help her concentrate on reading the last story because the story contained too many characters and the description of them was too brief. She said some characters were not fully described and all of a sudden popped up or disappeared; once in a while, she was confused about who was the speaker of the lines.

Fifth, WM, WK and SS. This illustration explained the participant used three strategies across three graded readers. One participant said that reading graded readers was a good opportunity to reinforce her vocabulary and grammatical rules and to broaden her view. She thus used the three strategies throughout three graded readers.

\section{Female participants' reducing the number of strategies}

Some participants used fewer strategies than the situation when they read the lower level of materials. The reasons were also presented. First, some less proficient readers stated that this was the first time they read English storybooks. They felt so curious about the material that they took a careful look at each word and each sentence in an effort to make a comparison with the articles in the textbook. Hence, they used WM and SS strategies. At the time of reading the third storybook, it was in the middle of the term. They were getting busy with other schoolwork and did not have much time to read it so they just read through the story quickly without checking any meanings of words or sentences.

Second, some participants described that when they read the first storybook at L2, they utilized two or three strategies. However, when they read the second and the third ones, they just used WK strategy. This is because they had seen these films and were familiar with the stories.

Third, a less proficient reader said that he used WM and WK strategies to read the first two readers. However, when he read the third one, he had no idea about the court and the law and thus he did not use WK. He spent much time looking up Chinese definition of words in the dictionary.

Fourth, a less-proficient reader pointed out that when he misunderstood some conversations in the first story, he stopped, reread each word, and analyzed sentence structures. When he read the second and third graded readers, he stated that the stories were overly simplified and he felt not interests in them and completed reading them by skipping some chapters. Under such condition, he said he just used WK strategy.

Fifth, when reading L2 graded reader, he used WM and SS strategies. This is because the story was short and he got sufficient time to read each word and each sentence. However, when he read L4 graded reader, he expressed that the amount of vocabulary and the length of the story increased and he was exhausted in handling the meanings of words and analyzing the sentence structure. Besides, he assumed that the vocabulary was the essential factor for understanding the story, so he just applied WM strategy.

\section{INSTRUCTIONAL SUGGESTIONS}

The results sketched in this study notified language instructors valuable knowledge that female and male students varied in their reading comprehension of graded readers at different difficulty levels. Along with Oxford's (2002) generalization of female superiority in verbal skills, the present study showed that female participants made much more progress in their reading comprehension than male participants. Moreover, the result of this study revealed that females used less time and more strategies to comprehend more difficult text. Armed with the results, some instructional suggestions were presented.

\section{A. Constructing the Conception of General Understanding}

During the process of comprehending an English text, most participants dedicated in associating written English words with their corresponding Chinese definitions (Lin, 2008). This result can be influenced by intensive reading instruction in class where the instructors teach students to comprehend a text by a fundamental decoding skill and word-by-word translation approach. Eventually students are trained to have a grasp of Chinese definitions-English words correspondences. With this result, the instructional suggestion is that the instructor should teach the students a concept of using strategies flexibly in extensive reading instead of using only one strategy focusing on analyzing linguistic information in the text. The instructor may also inform the students with the conception that the purpose of extensive reading is to have an overall, comprehensive understanding of the story so during the process of reading, the students may skip overly detailed ideas and use general schemes connecting a story (Lin, 2009b). The instructor may design a reading sheet composed of some critical thinking questions to guide the students' attention.

\section{B. Integrating the Reader's Word, Sentence, and World Knowledge}

The finding of the present study showed that females advanced considerably in the end of this program due to their use of their word, sentence, and world knowledge appropriately and flexibly. Most of the teenage readers already have had certain amount of such knowledge. All they need to do is use it in the right place at the right time. In this study, five illustrations of why the participants added strategies to comprehend more difficult text provided concrete examples. The 
instructor may demonstrate them to their students and lead them to practice integrating these types of knowledge.

\section{Selecting Reading Material Related to the Reader's Life Experience}

Most instructors assume that EFL learners' comprehension problems are related to deficiencies in general linguistic skills; thus, they are dedicated to the instruction of the vocabulary knowledge, the grammatical rules and other linguistic knowledge. However, as noted in the study, the participants' utilization of their WK is of great importance to foster their comprehension of graded readers at different difficulty levels. In this study, when the participants read graded readers issued with films, they could read through them in a short time. This finding suggests that the language instructor should notice the important role of the learner's world knowledge. The teacher may ask the students to select English stories relative to their life experience.

\section{APPENDIX POST-READING QUESTIONNAIRE}

Graded Reader: Level Title

1. When you read this level of graded reader, which strategies did you use to comprehend the stories?

A. The word meaning strategy.

B. The sentence structure strategy.

C. The world knowledge strategy

2. Why did you use these strategies to comprehend this story?

3. If there was one or more than one strategy you did not choose to comprehend this story, please write down your opinions why you didn't use them.

4. How much time did you use to finish reading this graded reader? hour(s).

\section{REFERENCES}

[1] Anderson, N. J. 1991. Individual differences in strategy use in second language reading and testing. Modern language Journal 75: 460-472.

[2] Bamford, J. 1984. Extensive reading by means of graded readers. Reading in a Foreign Language 2: 218-60.

[3] Bell, T. 2001. Extensive reading: Speed and comprehension. The Reading Matrix 1, no.1. http://www.reading matrix.com/articles/bell/index.html

[4] Block, E. 1986. The comprehension strategies of second language readers. TESOL Quarterly 20: 463-494.

[5] Brown, R. 2000. Extensive reading in the EFL class. JALT International Conference, Shizuoka, Japan.

[6] Camiciottoli, B. C. 2001. Extensive reading in English: Habits and attitudes of a group of Italian university EFL students. Journal of Research in Reading 24, no.2: 135-153.

[7] Chiu, M. M., and McBride-Chang, C. 2006. Gender, context, and reading: A comparison of student in 43 countries. Scientific studies of reading 10:331-362.

[8] Coady, J. 1997. L2 vocabulary acquisition through extensive reading. In J. Coady \& (), Second language vocabulary acquisition, ed. T. Huckin, 225-237. Cambridge, UK: Cambridge University Press.

[9] Day, R., and Bamford, J. 1998. Extensive reading in the second language classroom. Cambridge: Cambridge University Press.

[10] Day, R., and Bamford, J. 2002. Top ten principles for teaching extensive reading. Reading in a Foreign Language 14, no.2: $136-141$.

[11] Dreyer, C., and Oxford, R. L. 1996. Learning strategies and other predictors of ESL proficiency among Afrikaans speakers in South Africa. In Language learning strategies around the world: Cross-cultural perspectives, ed. R. L. Oxford, 61-74. Honolulu: University of Hawaii at Manoa.

[12] Elley, W. B. 1994. The IEA study of reading literacy: achievement and instruction in thirty-two school systems. Exeter, England: Pergamon.

[13] Garner, R. 1990. Children's use of strategies in reading. In Children's strategies: contemporary views of cognitive development, ed. D. Bjorklund. Hillsdale, NJ: Erlbaum.

[14] Grabe, W. 2002. Reading in a second language. In The Oxford handbook of applied linguistics, 49-59. NY: Oxford University Press.

[15] Green, J. M., and Oxford, R. 1995. A closer look at learning strategies, L2 proficiency, and gender. TESOL Quarterly 29: 261-297.

[16] Guthrie, J. T., and greaney, V. 1991. Literacy acts. In Handbook of reading research, eds. R. Barr, M. L. Kamil, P. Mosenthal, and P. D. Pearson, 68-96. NY: Longman.

[17] Hill, D. R. 1997. Setting up an extensive reading program: Practical Tips, The Language Teacher Online. The Language Teacher Online Available: http://langue.hyper.chubu.ac/lp/jalt/tlt/97/may/hill.html

[18] Hogrebe, M. C., Nist, S. L., and Newman, I. (1985). Are there gender differences in reading achievement? An investigation using the high school and beyond data. Journal of Educational Psychology 6: 716-724.

[19] Hosenfeld, C. 1977. A preliminary investigation of the reading strategies of successful and nonsuccessful second language learners. System 5: 110-123.

[20] Jacobs, G.., and Gallo, P. 2002. Reading alone together: Enhancing extensive reading via student-student cooperation in second-language instruction. Reading Online 5, no. 6. Available: http://www.readingonline/articles/jacobs/index.html 
[21] Krashen, S. 2001. Free voluntary reading: Still a very good idea. Selected Papers from the Tenth International Symposium on English Teaching, 47-58. Taipei: Crane.

[22] Lan, R., and Oxford, R. L. 2003. Language learning strategy profiles of elementary school students in Taiwan. International Review of Applied Linguistics in Language Teaching 41: 339-379.

[23] Lin, L.-F. (2008). A case study of a remedial extensive reading program in inspiring English learners' motivation to read English. Studies in English Language and Literature, 21, 91-102.

[24] Lin, L.-F. (2009a). Video segment comprehension strategies: Male and female university students. English Language Teaching, 2(3), 129-139.

[25] Lin, L.-F. (2009b). (in press). The impact of English learners' topic knowledge on reading comprehension: The application of the retelling technique. Studies in English Language and Literature, 24.

[26] Logan, S., and Johnston, R. 2009. Gender differences in reading ability and attitudes: Examining where these differences lie. Journal of Research in Reading 32:199-214.

[27] Lynch, J. 2002. Parents' self-efficacy beliefs, parents' gender, children's reader self-perceptions, reading achievement and gender. Journal of research in Reading 25:54-67.

[28] Lyon, G. R. Shaywitz, S. E., Shaywitz, B. A. 2003. A definition of dyslexia. Annals of Dyslexia 53:1-14.

[29] Massaro, D. W., and Millers, J. 1983. Working memory and individual differences in comprehension and memory of text. Journal of Educational Psychology 75: 314-318.

[30] Nation, P. 1997. The language learning benefits of extensive reading. The Language Teacher Online Available: http://langue.hyper.chubu.ac/jp/jalt/pub/tlt/97/may/extensive.html

[31] Nist, S., and Holschuh, J. 2000. Comprehension strategies at the college level. In Handbook of college reading and study strategy research, eds. R. Flippo \& D. Caverly, 75-104. NJ: Lawrence Erlbaum Associations, Publishers.

[32] Oxford, R. L. 1990. Language learning strategies: What every teacher should know. Boston, MA: Heinle \& Heinle.

[33] Oxford, R. L., and Ehrman, M. E. 1995. Adults' language learning strategies in an intensive foreign language program in the United States. System 23: 359-386.

[34] Oxford, R. (2002). Sources of variation in language learning. In The Oxford Handbook of Applied Linguistics, ed. R. Kaplan, 245-252. NY: Routledge.

[35] Phakiti, A. 2003. A closer look at gender and strategy use in L2 reading. Language Learning 53: 649-702.

[36] Poole, A. 2005. Gender differences in reading strategy use among ESL college students, Journal of College Reading and Learning 36, no. 1: 7-20.

[37] Powell, S. J. 2002. Extensive reading and its role in the future of English language teaching in Japanese high schools. English Language Teaching in Japan Online Available: www.extensivereading.net/er/powell.html

[38] Rosen, M. 2001. Gender differences in reading performance on documents across countries. Reading and Writing: An Interdisciplinary Journal 14: 1-38.

[39] Sarig, G. 1987. High-level reading in the first and in the foreign language: Some comparative process data. In Research in reading in English as a second language, eds. J. Devine, P. L. Carrell, and D. E. Eskey, 105-120. Washington, DC: TESOL.

[40] Sheorey, R., and Mokhtari, K. 2001. Differences in the metacognitive awareness of reading strategies among native and non-native readers. System 29: 431-449.

[41] Simpson, M. L., and Nist, S. L. (1997). Perspectives on learning history: A case study. Journal of Literacy Research 29: 363-395.

[42] Szoke, E., and sheorey, R. 2002. A comparative study of the learning strategies of Hungarian and Russian college students. Novelty 9:23-36.

[43] Vellutino, F.R., Scanlon, D.M., and Tanzman, M.S (1998). The case for early intervention in diagnosing specific reading disability. Journal of School Psychology 36: 367-397.

[44] Wigfield, A., Guthrie, J. T. 1997. Relations of children's motivation for reading to the amount and breath of their reading. Journal of educational Psychology 89: 420-432.

Lu-Fang Lin currently is an assistant professor in Institute of Applied Linguistics, National Taiwan Ocean University, Taiwan. She has over 20 years of experience in teaching English. She is presently involved in research on English remedial instruction, English reading comprehending instruction, and multimedia English teaching and learning. 